\title{
Modifications of Glass lonomer Cement Powder by Addition of Recently Fabricated Nano-Fillers and Their Effect on the Properties: A Review
}

\author{
Imran Alam Moheet ${ }^{1, \odot}$ Norhayati Luddin ${ }^{1, \odot}$ Ismail Ab Rahman ${ }^{1, \odot ~ T h i r u m u l u ~ P o n n u r a j ~ K a n n a n ~}{ }^{1, \odot}$ \\ Nik Rozainah Nik Abd Ghani ${ }^{1, \odot}$ Saman Malik Masudi²,๑
}

${ }^{1}$ School of Dental Sciences, Universiti Sains Malaysia, Kubang Kerian, Kelantan, Malaysia

2Department of Restorative Dentistry, Lincoln University College, Selangor, Malaysia

Address for correspondence Norhayati Luddin, BDS, DClindent, School of Dental Sciences, Universiti Sains Malaysia, Kubang Kerian, 16150 Kelantan, Malaysia (e-mail: norhayatikck@usm.my).

Eur J Dent 2019;13:470-477

\begin{abstract}
The aim of this article is to provide a brief insight regarding the recent studies and their recommendations related to the modifications to glass ionomer cement (GIC) powder in order to improve their properties. An electronic search of publications was made from the year 2000 to 2018. The databases included in the current study were EBSCOhost, PubMed, and ScienceDirect. The inclusion criteria for the current study include publication with abstract or full-text articles, original research, reviews or systematic reviews, in vitro, and in vivo studies that were written in English language. Among these only articles published in peer-reviewed journals were included. Articles published in other languages, with no available abstract and related to other nondentistry fields, were excluded. A detailed review of the recent materials used as a filler

Keywords

- glass ionomer cement

- powder modification

- physicomechanical properties

- nano-ceramics

- nano-fillers phase in GIC powder has revealed that not all modifications produce beneficial results. Recent work has demonstrated that modification of GIC powder with nano-particles has many beneficial effects on the properties of the material. This is due to the increase in surface area and surface energy, along with better particle distribution of the nano-particle. Therefore, more focus should be given on nano-particle having greater chemical affinity for $\mathrm{GIC}$ matrix as well as the tooth structure that will enhance the physicochemical properties of GIC.
\end{abstract}

\section{Introduction}

Glass ionomer cements (GICs) were developed in the 1960s by Alan Wilson and his team of co-workers as a replacement to dental silicate cements. ${ }^{1} \mathrm{GIC}$ has two main ingredients in its composition that are essential to maintain its desirable properties that include polymeric water-soluble acid and ion-leachable glass powder. GIC has been a popular restorative material due to its aesthetic properties, self-adhesive capability, antibacterial properties, and good biocompatibility. ${ }^{2,3}$ However, low mechanical properties and sensitivity to moisture have been a major hurdle for the widespread clinical applicability of this restorative material. ${ }^{4}$
A wide range of commercial hand-mixed and encapsulated GICs compositions are available to be used by the general dental practitioner in a clinical setting. These modifications have been carried out mostly in GIC powder to improve the mechanical properties of the restorative material. These modifications include incorporation of additives (metal, glass, and various nonreactive particles) as fillers in GIC matrix. ${ }^{5,6}$ These initial modifications increased the mechanical properties without having a negative impact on fluoride release capability of the material. However, these modifications did not have any chemical affiliation with the GIC matrix. ${ }^{7}$

In recent times, the GIC powder composition has undergone substantial modifications in its chemical makeup 
resulting in better handling characteristics and mechanical properties. These modifications in the chemical makeup of GIC powder are based on the hypothesis that greater polysalt bridges can be formed in the GIC matrix as a result of increasing the chemical affinity between the filler particles and GIC matrix. This will in turn enhance the mechanical properties of the material and make them a suitable posterior dental restorative material. ${ }^{8}$ Based on literature and intensive research work on GIC, the future holds promising prospects for clinical applicability of GIC in restorative dentistry.

\section{Aim and Objective}

Hence, the objective of this article was to provide an insight regarding the recent studies and recommendations related to the modifications to GIC powder in order to improve their properties.

\section{Review Method}

An electronic search of publications was made from the year 2000 to 2018. The electronic databases were accessed through an online portal. These databases included EBSCOhost, PubMed, and ScienceDirect. The inclusion criteria for the current study included publication with abstract or full-text articles, original research, reviews or systematic reviews, in vitro, and in vivo studies that were written in English language. Among these only articles published in peer-reviewed journals were included. Articles published in other languages, with no available abstract and related to other non-dentistry fields, were excluded. The keywords for the current study included the combination of following words: (1) GIC, (2) powder modification, (3) mechanical properties, (4) nano-ceramics, and (5) nano-fillers.

\section{Glass lonomer Cement Powder Modifications and Filler Incorporations}

\section{Metallic Powders}

To improvise on the earlier work, nano-silver (nano-Ag) particles were synthesized and added to conventional GIC (cGIC) by Paiva et al. Nano-Ag particles were developed using a unique polyacid formulations by a one-step photo-reduction in nano-Ag and added to a commercialized GIC powder with the intent of imparting antibacterial activity and enhancing mechanical properties. The resulting formulations contained nano-sized $(\sim 6 \mathrm{~nm})$ silver particle that were well dispersed in GIC matrix. MTT assay and Ag+ diffusion tests on nutritive agar plates were used to assess the antibacterial property of the modified cement. Paiva et al reported that the higher concentration of nano-Ag particles $(0.50 \% \mathrm{wt})$ improved handling characteristics of the modified cement and increased the compressive strength (CS) by $32 \%$ of nano-Ag-added GIC along with significant inhibition of microbial growth. ${ }^{9}$

The influence of incorporation of titanium oxide $\left(\mathrm{TiO}_{2}\right)$ nano-powder having a mean particle size of $21 \mathrm{~nm}$ to GIC was investigated. Following 24-hour water storage, a significant improvement in mean compressive fracture strength (CFS) value was reported with the addition of $\mathrm{TiO}_{2}$ nano-powder to GIC. ${ }^{5}$ More recently, $\mathrm{TiO}_{2}$ powder reinforcement strategy for GICs was tested with addition of 3 and $5 \mathrm{wt} \% \mathrm{TiO}_{2}$ into cGIC. Significant increase in flexural strength (FS) and CS compared to the cGIC was observed. However, there was no significant difference in shear bond strength (MPa) to natural tooth structure (enamel and dentin) between $\mathrm{TiO}_{2}$-added GIC and CGIC. $^{10}$

\section{Bioactive Glass}

Nowadays, many researchers focus on the bioactivation of GICs with the goal of enhancing their mechanical properties as well as improving their biological properties. ${ }^{11}$ GIC can bind chemically with the natural occurring apatite of enamel, dentin, and bone through the interaction of the aqueous polyacid. Hence, GIC can be considered bioactive material. Bioactive glass (BAG) was developed by Larry L Hench in 1969..$^{12,13}$ The BAG formed a stable bond or interface with biological tissues through the formation of an apatite layer. The first commercially available BAG had a composition of $46.1 \mathrm{~mol} \%$ silicon dioxide $\left(\mathrm{SiO}_{2}\right), 24.4 \mathrm{~mol} \%$ sodium oxide $\left(\mathrm{Na}_{2} \mathrm{O}\right), 2.6 \mathrm{~mol} \%$ phosphorus pentoxide $\left(\mathrm{P}_{2} \mathrm{O}_{5}\right)$, and $26.9 \mathrm{~mol} \%$ calcium oxide (CaO). This material was labeled as $45 \mathrm{~S} 5$ or Bioglass. ${ }^{12}$ Based on the composition of BAG added to GIC, the modified GICs have been shown to exhibit antimicrobial properties. ${ }^{14}$

A study was conducted to determine the effect of addition of BAG as fillers on CS, Young's modulus of elasticity, Vickers hardness, and fluoride ion release of modified GIC. ${ }^{11}$ Experimental BAG-added GIC samples were made by mixing 10 and $30 \mathrm{wt} \%$ of BAG particles with cGIC and resin-modified GIC (RMGIC) powders. It was reported that the CS of the modified material samples decreased with the increase in BAG filler particle content. The CS of BAG-added RMGIC was reported to increase during the immersion phase; however, it remained at a lower level than that of the cGIC. The BAG-added GIC materials had on average 55\% higher surface microhardness than the BAG-added RMGIC. The amount of fluoride $(F)$ ion release was significantly higher on all BAG-added RMGIC, being highest with BAG-added RMGIC with $30 \mathrm{wt} \%$ of BAG filler particles after 180 days of immersion.

In another study, two different types of BAG $(45 \mathrm{~S} 5 \mathrm{~F}$ and CF9) were incorporated to GIC in order to evaluate the physical and chemical properties along with biocompatibility of the BAG-added GIC combinations. ${ }^{15}$ In this formulation $\mathrm{Al}^{3+}$ was added as a modification to BAG particles as well as different sizes of BAG particles were used for modifications. The BAG-added GIC formulation was synthesized by the melt method. The material synthesized was then evaluated for setting time, CS, bioactivity and biocompatibility. It was concluded that addition of BAG particles improves the bioactivity of the CGIC, which was evident by the formation of an apatite layer. BAG (CF9)-added GIC displayed greater amount of apatite layer formation than BAG (45S5)-added GIC. Greater amount of BAG particles leads to increased bioactivity but decreases the $\mathrm{CS}$ of the modified material. The addition of $\mathrm{Al}^{3+}$ to the BAG composition improved the mechanical property of the material. However, it had a negative effect on the bioactivity of the material. BAGs with smaller particle sizes had no 
significant effect on bioactivity of the material but decreased the overall strength of the material. BAG (CF9)-added GIC formulation containing $10 \mathrm{~mol} \% \mathrm{Al}^{3+}$ gives the most promising result when added in $\leq 20 \mathrm{wt} \%$ to a cGIC. ${ }^{16}$

\section{Glass Fiber}

Several studies have been conducted to evaluate the effect of addition of glass fiber on the mechanical properties of GICs specifically fracture toughness and strength. ${ }^{17-19}$ The addition of short glass fibers $\left(\mathrm{CaO}-\mathrm{P}_{2} \mathrm{O}_{5}-\mathrm{SiO}_{2}-\mathrm{Al}_{2} \mathrm{O}_{3}\right)$ of varying lengths to a commercial hand-mixed GIC was reported by Kobayashi et al. ${ }^{17}$ The study reported that the addition of short glass fiber concentrations resulted in an increase in the mean diametral tensile strength (DTS) value. Similary, $\mathrm{SiO}_{2}-\mathrm{Al}_{2} \mathrm{O}_{3}-\mathrm{CaO}-\mathrm{NaF}-\mathrm{AlF}_{3}-\mathrm{Na}_{3} \mathrm{AlF}_{6}$ glass fibers addition to a variety of experimental GIC glass powders were also reported. ${ }^{20}$ The authors reported a significant improvement in the four-point flexural strength values for the glass fiber-added GIC. In another study, Lohbauer et al assessed the effect of addition of $20 \mathrm{vol} \%$ short fibers ( $430 \mathrm{~mm}$ ) on the total energy release and fracture toughness of GIC for dental applications. There was a significant increase in fracture toughness by $140 \%$ and the total energy release rate was increased by $440 \%$ as compared to the $\mathrm{CGIC}^{19}$

In a more recent study, Garoushi et al explored the effect of addition of hollow and solid discontinuous glass fiber fillers with varying loading fractions on fracture toughness, flexural strength, and CS of cGIC and RMGICs. ${ }^{21}$ Garoushi et al reported an increase in fracture toughness (280 and 200\%) and flexural strength (170 and $140 \%$ ) of hollow discontinuous glass fiber (10 wt \%)-added cGIC and RMGICs, respectively, as compared to unreinforced cGIC and RMGIC. ${ }^{21}$ However, there was no significant difference in CS between reinforced materials and control groups. As a concluding remark, short reactive fiber utilized by Lohbauer et al as filler agent for GIC has yielded the most favorable mechanical properties among various glass fiber compositions. ${ }^{19}$

\section{Hydroxyapatite $\left(\mathrm{Ca}_{10}\left(\mathrm{PO}_{4}\right)_{6}(\mathrm{OH})_{2}\right)$}

Though GICs have acceptable biocompatibility, many efforts have been made to increase the bioactivity of GIC by incorporating biologically active glasses. Hydroxyapatite (HA) has remarkable biological properties; it has a similar composition and crystal structure to the natural apatite found in human dental hard tissues as well as the human skeletal system..22 Many studies have tried to evaluate the effect of the addition of HA powders on the properties of GIC., ${ }^{8,23-26}$ The influence of addition of HA crystals to Fuji IX GIC powder was investigated by Yap et al. ${ }^{26}$ The modified GIC samples following water storage for 24 hours and 1 week reported no difference in mean CFS or DTS values for the $4 \%$ vol HA-added GIC when compared with the values cGIC. ${ }^{26}$ Further addition of the HA powder (12 and $28 \mathrm{vol} \%$ ) resulted in a marked decline in mean CFS and DTS values following 24 hours and 1 week water storage. ${ }^{26}$

It has been reported that nano-HA crystals favor remineralization of enamel..$^{27,28}$ Nano-HA has also been linked to the enhanced mechanical properties exhibited by nano-HA-added GIC. It was suggested that this increase in mechanical properties of nano-HA-added GIC was due to the ionic interaction between the polyacrylic acid and the apatite crystals. ${ }^{8}$

In a more recent study, nano-HA and nano-fluoroapatite (nano-FA) particles were synthesized using an sol-gel technique and these synthesized nanoparticles were incorporated into a commercialized GIC powder (Fuji II GC). ${ }^{8}$ The properties of modified GIC were assessed for compressive, diametral tensile, and biaxial flexural strengths. It was reported that the nano-HA and nano-FA-added cements exhibited increased CS (177-179 MPa), higher DTS (19-20 MPa), and higher biaxial flexural strength (26-28 MPa) as compared to CGIC. Moshaverinia et al concluded that GICs containing nano-bioceramics are promising dental restorative materials with improved mechanical properties as well as increased bond strength to the dentin. ${ }^{8}$ Additionally, it was suggested that by decreasing the particle size of HA from micrometer to nanometer scale, it increases their surface area remarkably. This could lead to the infiltration of the nano-crystals into dentine as well as enamel that may enhance bonding of GIC to tooth at the tooth-ionomer interface. ${ }^{29}$

\section{Silica}

Several scholars have tried to incorporate silica $\left(\mathrm{SiO}_{2}\right)$ in GIC matrix, aiming to improve their properties. ${ }^{30-34}$ Shiekh et al synthesized a nano-hydroxyapatite-silica (nano-HA-SiO${ }_{2}$ ) powder using one pot, sol-gel technique. ${ }^{32}$ The authors evaluated the Vickers microhardness of nano-HA-SiO${ }_{2}$-GIC having different formulations by wt $\%$ of $\mathrm{SiO}_{2}(11,21$, and $35 \%$ ). The samples were labeled as $\mathrm{HA}-11 \mathrm{SiO}_{2}, \mathrm{HA}-21 \mathrm{SiO}_{2}$, and HA- $35 \mathrm{SiO}_{2}$ based on their silica content. It was reported that 5 wt \% $\mathrm{HA}-35 \mathrm{SiO}_{2}$, when added to GIC, demonstrated the highest Vickers microhardness as compared to the remaining two formulations, over all giving an $\sim 73 \%$ increase as compared to cGIC. ${ }^{35}$ Moheet et al in continuation of this work demonstrated that addition of $\mathrm{HA}-35 \mathrm{SiO}_{2}$ to $\mathrm{GIC}$ enhanced the compressive, flexural, and shear bond strength of the material. ${ }^{36}$

In another study silica, fillers were added to RMGIC to assess for mechanochemical properties. Sodium-silicate-based formulation was used to synthesize silica through sol-gel method. The silica particles were added by wt \% to RMGIC powder and hand mixed as manufacturers recommendation. The authors concluded that addition of silica particles to RMGICs increased the mechanical properties and water sorption rates but decreased microleakage and water solubility. ${ }^{34}$

In a more recent study, a novel chlorhexidine-encapsulated mesoporous silica nano-particles (CHX@pMSN) was added to GIC. The authors reported that addition of 1 wt \% CHX@ pMSN to GIC effectively inhibited the growth of streptococcus mutans without affecting the mechanical properties of the material. It was suggested by the authors that addition of 1 wt \% CHX@pMSN into GIC can be used as a new strategy 
to prevent secondary caries, hence prolonging the life of the dental restorative material. ${ }^{33}$

\section{Hydroxyapatite $\left(\mathrm{Ca}_{10}\left(\mathrm{PO}_{4}\right)_{6}(\mathrm{OH})_{2}\right.$ and Zirconia $\left(\mathrm{ZrO}_{2}\right)$}

Zirconium and its subclasses, because of their good dimensional stability and high strength (on the same order as stainless-steel alloys), have been excessively used for fortifying and strengthening the brittle HA bioglasses in biomedical practices. $^{37,38}$ In one of the researches, hydroxyapatite-zirconia (HA-Zr) powder was substituted at $4,12,28$, and $40 \mathrm{vol} \%$ with the GIC powder constituent in Fuji IX GP capsules and was assessed for mechanical properties. ${ }^{25}$ The CFS and DTS of the 4 and $12 \mathrm{vol} \% \mathrm{HA}-\mathrm{Zr}$-added GIC reported no increase in the mean strength values when compared with the $\mathrm{CGIC}^{25} \mathrm{~A}$ decline in the mean CFS and DTS values was reported when the HA-Zr powder was added at higher ( 28 and $40 \mathrm{vol} \%$ ) concentrations. ${ }^{25}$

In another research, a nano-composite of HA, alumina/zirconia (HANBG), was synthesized using one-pot synthesis technique. This nano-composite was tested and compared with the cGIC for bioactivity, antibacterial, and mechanical properties. It was reported that the HANBG composite demonstrated an increase in hardness $(1.13 \mathrm{GPa})$ and Young's modulus (22.89 GPa) and an in vitro bioactivity was established with an increase in HA layer deposition. ${ }^{39}$

In a recent work on incorporation of nano-zirconia-silica-hydroxyapatite (nano-Zr-Si-HA) to GIC powder was done by Ab Rahman et al..$^{40}$ Nano-Zr-Si-HA powder was synthesized by one-pot sol-gel technique. The nano-Zr-Si-HA powder was substituted at 1 to $20 \mathrm{wt} \%$ with GIC powder under controlled manual grinding mechanism. ${ }^{40}$ The nano-Zr-Si-HA powder was characterized, and Vickers hardness of the nano$\mathrm{Zr}$-Si-HA-added GIC was evaluated. Vickers hardness in general was increased at lesser wt \% (1-5\%) and decreased as the concentration of the nano-Zr-Si-HA powder was increased in GIC powder. Highest Vickers hardness $(\sim 79.38 \mathrm{HV})$ was reported for $5 \mathrm{wt} \%$ nano-Zr-Si-HA-added GIC. ${ }^{40}$

\section{Zinc}

In recent times, application of GIC in orthopaedics has been restricted. This is due to the presence of aluminum in the glass composition of all commercially available GIC. It has been reported that aluminum inhibits a stable bond formation between GIC and bone resulting in defective bone mineralization. Since aluminum plays a pivotal role in the setting reaction of GIC, using an aluminum free glass powder will hinder cement formation. As an alternative to aluminum, zinc oxide $(\mathrm{ZnO})$ has been used in the glass formulations. $\mathrm{ZnO}$ has a dual effect; it acts as a network modifying oxide as well as forms an intermediate oxide similar to alumina. ${ }^{41}$

In a previous study, two different glasses with varying $\mathrm{Ca}^{2+}$ concentration based on Zn-silicate system were added to GIC. These modified GICs were tested for mechanical property and biocompatibility with the aim of synthesizing a cement for orthopaedic applications. ${ }^{42}$ The results for mechanical test were comparable to CGIC, but the modified GIC had poor handling characteristics. For glass formulation with lower calcium ion $\left(\mathrm{Ca}^{2+}\right)$ concentration, $\mathrm{Ca}^{2+}$ helped in replacing the $\mathrm{SiO}_{2}$ tetrahedra in the glass structure with $\mathrm{ZnO}_{4}$ tetrahedra. Remaining $\mathrm{Zn}$ ions modified the polymeric network, making it more susceptible to attack as a result increasing the bioactivity of the modified GIC. ${ }^{42}$

To improve the handling characteristics of zinc oxide (ZnO)-added GIC, Dickey et al produced a novel zinc-based GIC formulation with the addition of germanium dioxide $\left(\mathrm{GeO}_{2}\right)$, zirconium dioxide $\left(\mathrm{ZrO}_{2}\right)$, and sodium oxide $\left(\mathrm{Na}_{2} \mathrm{O}\right)$. The modified GIC was evaluated for the handling characteristics and mechanical properties. ${ }^{43}$ It was reported that the modified GIC exhibited better handling properties without affecting the mechanical properties of the modified GIC. The author suggested that this improvement in handling properties was as a result of replacement of $\mathrm{Si}$ by germanium $(\mathrm{Ge})$ as a network former. The authors describe this phenomenon as germanium $(\mathrm{Ge})$ glass network, holding one negative charge bonds with calcium $\left(\mathrm{Ca}^{2+}\right)$, sodium $\left(\mathrm{Na}^{+}\right)$, and zinc $\left(\mathrm{Zn}^{2+}\right)$ ions through one covalent bond, resulting in postponing their involvement in the setting reaction. Hence, improving the handling characteristics of the modified GIC. ${ }^{43,44}$

\section{Niobium Pentoxide}

Niobium pentoxide $\left(\mathrm{Nb}_{2} \mathrm{O}_{5}\right)$ is a metal oxide having a monoclinic structure. Addition of $\mathrm{Nb}_{2} \mathrm{O}_{5}$ to metals alloys has resulted in improving the mechanical properties of the alloys and exhibited fair biocompatibility and bioactivity. ${ }^{45}$ Bertolini et al prepared a glass powder based on the $4.5 \mathrm{SiO}_{2}-3 \mathrm{Al}_{2} \mathrm{O}_{3}-$ $\mathrm{Nb}_{2} \mathrm{O}_{5}-2 \mathrm{CaO}$ composition aiming to use this composition as GIC polymeric network formers. It was reported that increasing the $\mathrm{Nb}_{2} \mathrm{O}_{5}$ content of the GIC had a prolonging effect on the setting time of GIC. However, this addition had a negative impact on the mechanical properties of the modified GIC. ${ }^{46}$

In another study, the effect of addition of $\mathrm{Nb}_{2} \mathrm{O}_{5}$ on the physical and chemical properties of a newly synthesized GIC formulation. $\mathrm{Nb}_{2} \mathrm{O}_{5}$ particles having high purity were added at different wt \% (5-10\%) to cGIC powder. Being a metal oxide, addition of $\mathrm{Nb}_{2} \mathrm{O}_{5}$ improved the radio-opacity of the modified GIC and did not affect the physical and chemical properties of the material. The authors concluded that these results are positive and further investigations are required to analyze the biomimetic remineralization potential of this material. ${ }^{47}$

\section{Ytterbium Fluoride and Barium Sulfate}

In 2006, Prentice et al studied the effect of adding ytterbium fluoride $\left(\mathrm{YbF}_{3}\right)$ and barium sulfate $\left(\mathrm{BaSO}_{4}\right)$ particles to cGIC on the working time, setting time, surface hardness and CS of a cGIC. ${ }^{48} \mathrm{YbF}_{3}$ and $\mathrm{BaSO}_{4}$ nano-particles were added separately into the cGIC powder at different wt \% (1-25\%). This resulted in a reduction in working and initial setting times. Surface hardness was increased with addition of 1 to $2 \mathrm{wt}$ $\%$ of either $\mathrm{YbF}_{3}$ and $\mathrm{BaSO}_{4}$ and decreased surface hardness was observed at higher wt \% of either $\mathrm{YbF}_{3}$ and $\mathrm{BaSO}_{4}$. $\mathrm{CS}$ was decreased with the addition of either $\mathrm{YbF}_{3}$ or $\mathrm{BaSO}_{4}$ and continued to decrease at higher concentration of filler particles. This effect was more noticeable for $\mathrm{BaSO}_{4}$ addition, where 
even $1 \mathrm{wt} \%$ addition in the GIC powder resulted in a drop of more than $10 \%$ in strength, from 160 to $142 \mathrm{MPa}$. Meanwhile higher concentration of $\mathrm{YbF}_{3}$ nano-particles decreased the strength of the modified GIC. These modified GICs containing $25 \mathrm{wt} \%$ of $\mathrm{YbF}_{3}$ were still strong enough to pass the ISO standard for dental restorative materials. The authors suggested that these nano-particles modified the setting characteristics, strength, and surface hardness of GIC. Hence, they may be useful for refining the handling characteristics of GICs in clinical applications. ${ }^{48}$

\section{Casein Phosphopeptide-Amorphous Calcium Phosphate}

Casein phosphopeptide-amorphous calcium phosphate (CPP-ACP) nano-complexes have been shown to prevent demineralization and promote remineralization of enamel. ${ }^{49-51}$ Oshiro et al used CPP-ACP paste on bovine teeth to demonstrate its remineralizing potential. Bovine teeth specimens' blocks were made and placed in lactic acid (demineralizing solution) that were then stored in artificial saliva. Remaining bovine tooth specimens were stored in CPP-ACP paste solution first and then placed in demineralizing solution followed by storage in artificial saliva. Scanning electron microscopy (SEM) was utilized to observe morphological features. The authors reported that the specimens that were treated with CPP-ACP first showed little morphological changes when exposed to acidic medium as compared to the remaining specimens. Hence, it was suggested by the authors that CPP-ACP has the ability to prevent demineralization. ${ }^{50}$ Following that effect of different acidic and neutral medium on the surface hardness, mass and ion release property of CPP-ACP-added GIC were assessed. It was reported that the incorporation of $3 \mathrm{wt} \% \mathrm{CPP}$-ACP into GIC not only enhanced calcium and phosphate ion release, but it also had no adverse effect on the fluoride ion release. No change in surface hardness and mass change was also reported. The authors recommended that CPP-ACP-added GIC has the potential to inhibit demineralization of teeth associated with caries and erosion. $^{52}$

\section{Forsterite}

In recent time, biomaterial research has shifted its focus from $\mathrm{HA}$ to other bioactive materials. Forsterite $\left(\mathrm{Mg}_{2} \mathrm{SiO}_{4}\right)$ glass is an important material based on magnesia-silica system. As compared to HA, it has demonstrated substantial enhancement in the fracture toughness of the material as well as in vitro osteoblastic adhesion..$^{33}$ In 2014, a study was conducted to investigate the effect of forsterite nano-particles on the mechanical properties (compressive, flexural, and DTS) of GIC. The forsterite nano-particles were synthesized using a sol-gel technique and were added to cGIC powder at 1 to $4 \mathrm{wt} \%$. It was reported that the addition of $1 \mathrm{wt} \%$ forsterite to cGIC leads to an increase in compressive, flexural, and DTS of the modified material. ${ }^{54}$ However, the fluoride ion release property of the modified material was slightly less than the cGIC. ${ }^{55}$ Hence, it was suggested that forsterite-added GIC may be used as a dental restorative material and bone cement.

\section{Strontium}

According to ISO standard, GIC should be an opaque material. To fulfil this requirement, researchers have tried to modify the glass component of GIC by replacing Ca with strontium (Sr). The exact science behind the effect of this replacement on the setting process of GIC is not fully understood and neither investigated. In a recent investigation, a novel $\mathrm{Al}$ free $\mathrm{Sr}-\mathrm{SiO}_{2}$ glasses were prepared by substituting magnesium ( $\mathrm{Mg}$ ) partially $(\mathrm{x})$ with $\mathrm{SrO}$ based on $\mathrm{SiO}_{2}-\mathrm{P}_{2} \mathrm{O}_{5}-\mathrm{CaO}-\mathrm{ZnO}-\mathrm{MgO}$ $\left(1_{-x}\right)-\mathrm{SrO}_{\mathrm{x}}-\mathrm{CaF}_{2}$. The mechanical properties of this modified GICs with SrO substitution at $\mathrm{X}=0.25$ were significantly increased. The mechanical properties gradually decreased with further increase in the strontium. ${ }^{56}$ In recent times, many dental biomaterials are being experimented with the addition of $\mathrm{Sr}$ to reduce the microbial contamination. Brauer et al added $\mathrm{Sr}$ to a bone cement based on BAG. In vitro results showed that the bactericidal action of the cement was enhanced through substituting $\mathrm{Sr}$ in BAG containing bone cement. ${ }^{57}$

\section{Montmorillonite Clay}

Montmorillonite clay (MMT) is a trilayered smectite clay consisting of stacked platelets constructed of an alumina layer sandwiched between two silica layers. The nano-clay when treated with an organic surfactants (intercalants), such as 12-amino-dodecanoicacid, resulted in producing organically modified clay known as 12 -amino-dodecanoicacid treated montmorillonite (ADA-MMT) clay..$^{58}$ In one of the successful attempts to add nano-clay as an additive to GIC, Dowling et al in their study successfully combined two types of nano-clay, an inorganic calcium montmorillonite (Ca-MMT) and an organic ADA-MMT clay to CGIC at 0.5 to $2.5 \mathrm{wt} \%$. It was reported that the CS of the cement increased with the addition of ADA-MMT. In contrast, addition of Ca-MMT resulted in the reduction in CS of the modified material as compared to cGIC. Dowling et al suggested that increased interlayer space between the nano-clay may provide an opening for the polyacid chains in the GIC matrix to interact with the MMT galleries. Thus, it enhanced the CS of the modified GIC. ${ }^{59}$

Recently, Fareed and Stamboulis reported slight improvement in mechanical property when nano-clay was added as reinforcement by 2 wt \%. ${ }^{60}$ It was reported that dispersion nano-clay with less than $2 \mathrm{wt} \%(1-2.0 \mathrm{wt} \%)$ when added to cGIC may successfully produce a mechanical strong material..$^{60}$ More recently, Fareed and Stamboulis reported that cements (Hifi GIC) containing nano-clay (4 wt \%) generally presented with increased total wear rate when compared to cGIC. The hardness value reported was between 62 and 89 HV. However, there was no significant difference in hardness between the modified GIC and cGIC. ${ }^{61}$

\section{Cellulose Microfibers/Cellulose Nano-Crystals}

In order to improve the mechanical properties of cGIC, Silva et al evaluated the effect of addition of cellulose microfibers $(\mathrm{CmF})$ and cellulose nano-crystals (CnCs) to GICs. Cellulose microfibers and CnCs were added to the GIC powder at different wt \%, while it was being manipulated. The modified 
GIC specimens were then submitted for mechanical testing. Silva et al concluded that the addition of only small concentrations of $\mathrm{CnC}$ to GIC led to significant improvements in all the mechanical properties: CS, DTS, and elastic modulus increased by 110,53 , and $161 \%$, respectively. Therefore, $\mathrm{CnC}$ may represent as a new potential permanent filler particle for dental restorative materials. ${ }^{62}$

\section{Cellulose Nano-Crystals and Titanium Oxide}

In a recent study, CnCs were used in combination with titanium oxide $\left(\mathrm{TiO}_{2}\right)$ nano-particles as an additive to GIC. CnCs were prepared using sisal $\mathrm{CnC}$ whicker in a dispersion liquid, while nano- $\mathrm{TiO}_{2}$ were prepared by a sol-gel technique. It was reported that the physical properties of the modified GIC reinforced with $2 \mathrm{wt} \% \mathrm{TiO}_{2}$ nano-particles and $1 \mathrm{wt} \%$ of $\mathrm{CnC}$ showed significant improvement; similarly CS was increased by $18.9 \%$ and the shear bond strength increased to $151 \%$ when tested on enamel of extracted teeth. Therefore, it was concluded that the combination of $\mathrm{CnC}$ and titanium nano-particles modified GIC represents a promising restorative dental material for surface applications. ${ }^{63}$

\section{Fluorinated Graphene}

Sun et al have recently attempted an addition of fluorinated graphene (FG) to cGIC in order to enhance mechanical properties and antibacterial properties of GICs, with the expectations of not weakening their $\mathrm{F}$ ion releasing property. White colored FG was synthesized using graphene oxide through a hydrothermal reaction. Four different wt \% FG (0.5-4 wt \%) were added to cGIC powder and submitted for testing. It was concluded that the addition of FG to cGIC enhanced their mechanical and tribological properties. Antibacterial efficacy of the modified GIC was also increased. In addition, the incorporation of FG to GIC had no negative affect on the color, solubility, and $\mathrm{F}$ ion release property of the material. This finding seems to open a new direction for application of FG in restorative dentistry. ${ }^{64}$

\section{Conclusion}

A detailed review of the recent materials used as a filler phase in GIC powder has revealed that addition of lower percentage of filler content has demonstrated better mechanical properties and not all modifications produce beneficial results. None of the additions had any beneficial effect on the moisture sensitivity of GIC. Addition of barium resulted in poor handling characteristics, while forsterite effected the fluoride release of the GIC. A lot of work has been done on bioactive glasses and nano-particles. The BAG tends to increase the poly-salt bridges in the GIC matrix and forms a stable bond or interface with biological tissues through the formation of an apatite layer, resulting in better mechanical properties. Recent work has demonstrated that by adding nano-particle such as nano- $\mathrm{TiO}_{2}$, nano-HA, nano-SiO ${ }_{2}$, and nano- $\mathrm{ZrO}_{2}$ particles in GIC increase the mechanical properties significantly. This is due to the increase in surface area and surface energy, along with better particle distribution. Therefore, more work should be focused on nano-particles as they have greater chemical affinity for GIC matrix as well as the tooth structure; thus, it would enhance the physicochemical properties of GIC.

\section{Clinical Significance}

The incorporation of various nano-particles into GIC improved the physical-mechanical and antimicrobial properties of the said material. As such, these modifications could be used as additional fillers in GIC. Thus, these modifications could enhance the dental application of GIC as a restorative material.

\section{Funding}

This work was supported by the Malaysian Ministry of Higher Education under Fundamental Research Grant Scheme (FRGS/203/PPSG/6171173).

\section{Conflict of Interest}

Dr. Luddin reports grants from Fundamental Research Grant Scheme, during the conduct of the study; Dr. Moheet reports grants from Fundamental Research Grant Scheme, during the conduct of the study. The other authors have no conflicts of interest to disclose.

\section{Acknowledgement}

Imran Alam Moheet would like to thank USM for providing the USM global fellowship.

\section{References}

1 Wilson AD, Kent BE. A new translucent cement for dentistry. The glass ionomer cement. Br Dent J 1972;132(4):133-135

2 Najeeb S, Khurshid Z, Zafar MS, et al. Modifications in glass ionomer cements: nano-sized fillers and bioactive nanoceramics. Int J Mol Sci 2016;17(7):E1134

3 Ching HS, Luddin N, Kannan TP, Ab Rahman I, Abdul Ghani NR. Modification of glass ionomer cements on their physical-mechanical and antimicrobial properties. J Esthet Restor Dent 2018;30(6):557-571

4 Berg JH, Croll TP. Glass ionomer restorative cement systems: an update. Pediatr Dent 2015;37(2):116-124

5 Elsaka SE, Hamouda IM, Swain MV. Titanium dioxide nanoparticles addition to a conventional glass-ionomer restorative: influence on physical and antibacterial properties. J Dent 2011;39(9):589-598

6 Kobayashi M, Kon M, Asaoka K, Miyai K. Strengthening of glass-ionomer cement by compounding short glass-fibers. J Dent Res 2000;79:539-539

7 Sajjad A, Bakar WZ, Mohamad D, Kannan T. Various recent reinforcement phase incorporations and modifications in glass ionomer powder compositions: a comprehensive review. J Int Oral Health 2018;10(4):161-167

8 Moshaverinia A, Ansari S, Moshaverinia M, Roohpour N, Darr JA, Rehman I. Effects of incorporation of hydroxyapatite and fluoroapatite nanobioceramics into conventional glass ionomer cements (GIC) Acta Biomater 2008;4(2):432-440

9 Paiva L, Fidalgo TKS, da Costa LP, et al. Antibacterial properties and compressive strength of new one-step preparation silver nanoparticles in glass ionomer cements (NanoAg-GIC) J Dent 2018;69:102-109

10 Garcia-Contreras R, Scougall-Vilchis RJ, Contreras-Bulnes R, Sakagami H, Morales-Luckie RA, Nakajima H. Mechanical, antibacterial and bond strength properties of 
nano-titanium-enriched glass ionomer cement. J Appl Oral Sci 2015;23(3):321-328

11 Yli-Urpo H, Lassila LVJ, Närhi T, Vallittu PK. Compressive strength and surface characterization of glass ionomer cements modified by particles of bioactive glass. Dent Mater 2005;21(3):201-209

12 Hench LL, Xynos ID, Polak JM. Bioactive glasses for in situ tissue regeneration. J Biomater Sci Polym Ed 2004;15(4):543-562

13 Farooq I, Moheet IA, Alshwaimi E. Cavity cutting efficiency of a Bioglass TM and alumina powder combination utilized in an air abrasion system. Bull Mater Sci 2016;39(6):1531-1536

14 Yli-Urpo $H$, Närhi $T$, Söderling E. Antimicrobial effects of glass ionomer cements containing bioactive glass (S53P4) on oral micro-organisms in vitro. Acta Odontol Scand 2003;61(4):241-246

15 De Caluwé T, Vercruysse CWJ, Declercq HA, Schaubroeck D, Verbeeck RMH, Martens LC. Bioactivity and biocompatibility of two fluoride containing bioactive glasses for dental applications. Dent Mater 2016;32(11):1414-1428

16 De Caluwé T, Vercruysse CWJ, Ladik I, et al. Addition of bioactive glass to glass ionomer cements: effect on the physico-chemical properties and biocompatibility. Dent Mater 2017;33(4):e186-e203

17 Kobayashi M, Kon M, Miyai K, Asaoka K. Strengthening of glass-ionomer cement by compounding short fibres with $\mathrm{CaO}-\mathrm{P}_{2} \mathrm{O}_{5}-\mathrm{SiO}_{2}-\mathrm{Al}_{2} \mathrm{O}_{3}$ glass. Biomaterials 2000;21(20):2051-2058

18 Kawano F, Kon M, Kobayashi M, Miyai K. Reinforcement effect of short glass fibers with $\mathrm{CaO}-\mathrm{P}(2) \mathrm{O}(5)-\mathrm{SiO}(2)-\mathrm{Al}(2)$ $\mathrm{O}(3)$ glass on strength of glass-ionomer cement. J Dent 2001;29(5):377-380

19 Lohbauer U, Frankenberger R, Clare A, Petschelt A, Greil P. Toughening of dental glass ionomer cements with reactive glass fibres. Biomaterials 2004;25(22):5217-5225

20 Lohbauer U, Walker J, Nikolaenko S, et al. Reactive fibre reinforced glass ionomer cements. Biomaterials 2003;24(17):2901-2907

21 Garoushi S, Vallittu P, Lassila L. Hollow glass fibers in reinforcing glass ionomer cements. Dent Mater 2017;33(2):e86-e93

22 Farooq I, Moheet IA, AlShwaimi E. In vitro dentin tubule occlusion and remineralization competence of various toothpastes. Arch Oral Biol 2015;60(9):1246-1253

23 Lucas ME, Arita K, Nishino M. Strengthening a conventional glass ionomer cement using hydroxyapatite. J Dent Res 2001;80:711

24 Lucas ME, Arita K, Nishino M. Toughness, bonding and fluoride-release properties of hydroxyapatite-added glass ionomer cement. Biomaterials 2003;24(21):3787-3794

25 Gu YW, Yap AU, Cheang P, Khor KA. Effects of incorporation of $\mathrm{HA} / \mathrm{ZrO}(2)$ into glass ionomer cement (GIC) Biomaterials 2005;26(7):713-720

26 Yap AUJ, Pek YS, Kumar RA, Cheang P, Khor KA. Experimental studies on a new bioactive material: HAIonomer cements. Biomaterials 2002;23(3):955-962

27 Huang S, Gao S, Cheng L, Yu H. Remineralization potential of nano-hydroxyapatite on initial enamel lesions: an in vitro study. Caries Res 2011;45(5):460-468

28 Huang SB, Gao SS, Yu HY. Effect of nano-hydroxyapatite concentration on remineralization of initial enamel lesion in vitro. Biomed Mater 2009;4(3):34-104

29 Lee JJ, Lee YK, Choi BJ, et al. Physical properties of resin-reinforced glass ionomer cement modified with micro and nano-hydroxyapatite. J Nanosci Nanotechnol 2010;10(8):5270-5276

30 Tjandrawinata R, Irie M, Suzuki K. Marginal gap formation and fluoride release of resin-modified glass-ionomer cement: effect of silanized spherical silica filler addition. Dent Mater J 2004;23(3):305-313
31 Hatanaka K, Irie M, Tjandrawinata R, Suzuki K. Effect of spherical silica filler addition on immediate interfacial gap-formation in Class V cavity and mechanical properties of resin-modified glass-ionomer cement. Dent Mater J 2006;25(3):415-422

32 Shiekh RA, Ab Rahman I, Masudi SM, Luddin N. Modification of glass ionomer cement by incorporating hydroxyapatite-silica nano-powder composite: Sol-gel synthesis and characterization. Ceram Int 2014;40(2):3165-3170

33 Yan H, Yang H, Li K, Yu J, Huang C. Effects of chlorhexidine-encapsulated mesoporous silica nanoparticles on the anti-biofilm and mechanical properties of glass ionomer cement. Molecules 2017;22(7):1225

34 Felemban NH, Ebrahim MI. Effects of adding silica particles on certain properties of resin-modified glass-ionomer cement. Eur J Dent 2016;10(2):225-229

35 Rahman IA, Masudi SAM, Luddin N, Shiekh RA. One-pot synthesis of hydroxyapatite-silica nanopowder composite for hardness enhancement of glass ionomer cement (GIC) Bull Mater Sci 2014;37(2):213-219

36 Moheet IA, Luddin N, Ab Rahman I, Masudi SaM, Kannan TP, Abd Ghani NR. Evaluation of mechanical properties and bond strength of nano-hydroxyapatite-silica added glass ionomer cement. Ceram Int 2018;44(8):9899-9906

37 Elie ED, Maha A-G. The zirconia restoration properties: a versatile restorative material. Dentistry. 2014;4(4)

38 Rajabzadeh G, Salehi S, Nemati A, Tavakoli R, Solati Hashjin M. Enhancing glass ionomer cement features by using the HA/YSZ nanocomposite: a feed forward neural network modelling. J Mech Behav Biomed Mater 2014;29:317-327

39 Anusha Thampi VV, Prabhu M, Kavitha K, et al. Hydroxyapatite, alumina/zirconia, and nanobioactive glass cement for tooth-restoring applications. Ceram Int 2014; 40(9, Part A) :14355-14365

40 Ab Rahman I, Ghazali NAM, Bakar WZ, Masudi SM. Modification of glass ionomer cement by incorporating nanozirconia-hydroxyapatite-silica nano-powder composite by the one-pot technique for hardness and aesthetics improvement. Ceram Int 2017;43(16):13247-13253

41 Xie D, Feng D, Chung I-D, Eberhardt AW. A hybrid zinc-calcium-silicate polyalkenoate bone cement. Biomaterials 2003;24(16):2749-2757

42 Boyd D, Towler MR. The processing, mechanical properties and bioactivity of zinc based glass ionomer cements. J Mater Sci Mater Med 2005;16(9):843-850

43 Dickey BT, Kehoe S, Boyd D. Novel adaptations to zinc-silicate glass polyalkenoate cements: the unexpected influences of germanium based glasses on handling characteristics and mechanical properties. J Mech Behav Biomed Mater 2013;23:8-21

44 Khader BA, Peel SAF, Towler MR. An injectable glass polyalkenoate cement engineered for fracture fixation and stabilization. J Funct Biomater 2017;8(3):E25

45 Leitune VC, Collares FM, Takimi A, et al. Niobium pentoxide as a novel filler for dental adhesive resin. J Dent 2013;41(2):106-113

46 Bertolini MJ, Palma-Dibb RG, Zaghete MA, Gimenes R. Evaluation of glass ionomer cements properties obtained from niobium silicate glasses prepared by chemical process. J Non-Cryst Solids 2005;351(6-7):466-471

47 Garcia IM, Leitune VCB, Balbinot GS, Samuel SMW, Collares FM. Influence of niobium pentoxide addition on the properties of glass ionomer cements. Acta Biomater Odontol Scand 2016;2(1):138-143

48 Prentice LH, Tyas MJ, Burrow MF. The effect of ytterbium fluoride and barium sulphate nanoparticles on the reactivity and strength of a glass-ionomer cement. Dent Mater 2006;22(8):746-751 
49 Al Zraikat H, Palamara JE, Messer HH, Burrow MF, Reynolds EC. The incorporation of casein phosphopeptide-amorphous calcium phosphate into a glass ionomer cement. Dent Mater 2011;27(3):235-243

50 Oshiro M, Yamaguchi K, Takamizawa T, et al. Effect of CPP-ACP paste on tooth mineralization: an FE-SEM study. J Oral Sci 2007;49(2):115-120

51 Farooq I, Moheet IA, Imran Z, Farooq U. A review of novel dental caries preventive material: casein phosphopeptide-amorphous calcium phosphate (CPP-ACP) complex. King Saud University Journal Of Dental Sciences 2013;4(2):47-51

52 Zalizniak I, Palamara JE, Wong RH, Cochrane NJ, Burrow MF, Reynolds EC. Ion release and physical properties of CPP-ACP modified GIC in acid solutions. J Dent 2013;41(5):449-454

53 Ni S, Chou L, Chang J. Preparation and characterization of forsterite $\left(\mathrm{Mg}_{2} \mathrm{SiO}_{4}\right)$ bioceramics. Ceram Int 2007;33(1):83-88

54 Sayyedan FS, Fathi MH, Edris H, Doostmohammadi A, Mortazavi V, Hanifi A. Effect of forsterite nanoparticles on mechanical properties of glass ionomer cements. Ceram Int 2014;407, Part B :10743-10748

55 Sayyedan FS, Fathi M, Edris H, Doostmohammadi A, Mortazavi $\mathrm{V}$, Shirani F. Fluoride release and bioactivity evaluation of glass ionomer: forsterite nanocomposite. Dent Res J (Isfahan) 2013;10(4):452-459

56 Kim DA, Abo-Mosallam HA, Lee HY, Kim GR, Kim HW, Lee HH. Development of a novel aluminum-free glass ionomer cement based on magnesium/strontium-silicate glasses. Mater Sci Eng c 2014;42:665-671
57 Brauer DS, Karpukhina N, Kedia G, et al. Bactericidal strontium-releasing injectable bone cements based on bioactive glasses. J R Soc Interface 2013;10(78):20120647

58 Sinha Ray S, Okamoto M. Polymer/layered silicate nanocomposites: a review from preparation to processing. Prog Polym Sci 2003;28(11):1539-1641

59 Dowling AH, Stamboulis A, Fleming GJP. The influence of montmorillonite clay reinforcement on the performance of a glass ionomer restorative. J Dent 2006;34(10):802-810

60 Fareed MA, Stamboulis A. Effect of nanoclay dispersion on the properties of a commercial glass ionomer cement. Int J Biomater 2014;2014:685389

61 Fareed MA, Stamboulis A. Nanoclay-reinforced glass-ionomer cements: in vitro wear evaluation and comparison by two wear-test methods. Dent J (Basel) 2017;5(4):28

62 Silva RM, Pereira FV, Mota FA, Watanabe E, Soares SM, Santos $\mathrm{MH}$. Dental glass ionomer cement reinforced by cellulose microfibers and cellulose nanocrystals. Mater Sci Eng C 2016;58:389-395

63 Sun J, Xu Y, Zhu B, et al. Synergistic effects of titanium dioxide and cellulose on the properties of glassionomer cement. Dent Mater J 2019;38(1):41-51

64 Sun L, Yan Z, Duan Y, Zhang J, Liu B. Improvement of the mechanical, tribological and antibacterial properties of glass ionomer cements by fluorinated graphene. Dent Mater 2018;34(6):e115-e127 